\title{
Brokers as Catalysts for the E-Health Market
}

\author{
Vivian Vimarlund ${ }^{1,2}$, Craig Kuziemsky³, Christian Nøhr4, Pirkko Nykänen5, Nicolas Nikula6 \\ ${ }^{1}$ International Business School, Jönköping University, Jönköping, Sweden \\ ${ }^{2}$ Department of Computer and Information Science/Human-Centered Systems, Linköping University, Linköping, Sweden \\ ${ }^{3}$ University of Ottawa, Ottawa, Canada \\ ${ }^{4}$ Aalborg University, Aalborg, Denmark \\ ${ }^{5}$ University of Tampere, Tampere, Finland \\ ${ }^{6}$ Post-Nord, Stockholm, Sweden \\ Email: Vivian.Vimarlund@liu.se, Vivian.Vimarlund@ju.se
}

How to cite this paper: Vimarlund, V., Kuziemsky, C., Nøhr, C., Nykänen, P. and Nikula, N. (2017) Brokers as Catalysts for the E-Health Market. Intelligent Information Management, 9, 177-188. https://doi.org/10.4236/iim.2017.95009

Received: July 15, 2017

Accepted: August 21, 2017

Published: August 24, 2017

Copyright $\odot 2017$ by authors and Scientific Research Publishing Inc. This work is licensed under the Creative Commons Attribution International License (CC BY 4.0).

http://creativecommons.org/licenses/by/4.0/

\begin{abstract}
In this study we use the experiences from the service industry and explore pre-requisites of the e-health market which will need to achieve to stimulate both sides of the market (vendors, healthcare organizations, government, institutions, corporations and services organizations) to interact with each other and develop demand driven services and social innovations. The results presented in this paper may be of interest for decision makers, industries (e.g. software or technology designers), small and medium enterprises (SME) and entrepreneurs with an interest in becoming a part of the e-health market, and for consumers (e.g. healthcare personnel and patients) that are willing to influence the market through their choices. The outcomes of the study shown that the role of virtual brokers is essential to the further development of a sustainable e-health market globally because its role as catalyst for interaction between the two-sides of the markets, its effects on the reduction of competitive constrains, its effects on the accessibility to broader network of actors and its effects on the support of public-private exchanges of knowledge and experience.
\end{abstract}

\section{Keywords}

Virtual Brokers, Two-Sided E-Health Market, Demand Driven Services, Social Innovations

\section{Introduction}

Over the last few years, the trend has been to innovate healthcare delivery through increasing patient involvement and engagement as part of developing a 
patient-centered e-health system [1] [2] [3] [4]. For this reason, much effort has been put to improve interactions between and within producers and consumers of healthcare services in order to co-create social innovations ${ }^{1}$ [4] [5]. Strategies have been developed around the world to meet the challenges that the transition to a more patient-centered system demands [6] [7]. In parallel with this, the e-health industry ${ }^{2}$ continues to expand as a push market ${ }^{3}$. Vendors develop products that are aimed to address the healthcare challenges of the millennium (e.g. Improve productivity, personalized medicine, round the clock monitoring, and empowerment of patients) and to find arenas for interaction between producers and consumers and private and public actors to identify and co-create demand driven services that match preferences and needs of consumers (e.g. healthcare organizations and patients) [8].

Demand driven innovations are essential for companies to remain competitive in an increasingly complex, uncertain and changing environment such as the e-health market. While the possibility exists to increase adaptability while providing several direct benefits to the producers and, consequently, to its customers, e.g. quicker and cheaper innovation cycles, reduction of transaction costs, access to embedded information, etc., the co-creation of social innovations presupposes the existence of catalysts that make the right connections and links between producers and seekers of services while also facilitating the interaction between the two sides of the market. In the past, the discussion about issues that can contribute to developing a sustainable market for e-health services has been limited to identifying issues related to defining, designing and implemented specific e-health services. The market for social e-health innovations, however, in addition to offer good comercializable ideas that spin out new business, or that improve existing business, has shown the need to more proactively use virtual platforms as tools for to facilitate matching between the two sides of the market [12] [13] [14] and as a mediator that bring benefits, tangible and intangible, to both sides [15].

In this study we use the experiences from the service industry to explore pre-requisites the e-health market needs to achieve to stimulate both sides of the market (vendors, healthcare organizations, government, institutions, corporations and services organizations) to interact with each other, and to develop demand driven services and social innovations. The results of this study may be of interest for decision makers, industries (e.g. software or technology designers), small and medium enterprises (SME) and entrepreneurs who are interested in

${ }^{1}$ Social innovations include several different actors that cross the boundaries of organizations to innovate and co-produce services. Social innovations in a healthcare context include actors from both public and private organizations [9].

${ }^{2}$ E-health refers to health services and information delivered or enhanced through the Internet and related technologies. In a broader sense, the term characterizes not only a technical development, but also a state-of-mind, a way of thinking, an attitude, and a commitment for networked, global thinking, to improve health care locally, regionally, and worldwide by using information and communication technology [10].

${ }^{3}$ The e-health market was estimated to have a market size of approximate USD 85.44 billion in 2014 and is expected to reach USD 308.0 billion by 2022 [11]. 
becoming a part of the e-health market in the future, and for consumers (e.g. healthcare personnel and patients) who are willing to influence the market through their choices.

\section{Method}

The present study is based on previous research that was performed by the authors and reported in a book entitled "E-health two sided markets: Implementation and business models, 2016". We use also experiences from one service industry that uses virtual platforms as brokers which enable parties to benefit from trade or from interactions with partnerships. These benefits arise because the parties enjoy a reduction of transactions costs by minimizing costs for duplication, advertising and media support. We also use information that was obtained from a series of interviews and from a literature review that was performed in two previous studies [16] [17]. The first of these studies identified the challenges that customers and providers consider of importance to develop a sustainable market for social innovations. The second study sampled knowledge about challenges and opportunities associated with the development of a market for social innovations. We use the knowledge gained in those studies to illustrate the demands and expectations consumers and entrepreneurs have to join the e-health market and to compare expectations from the two sides of the e-health market with the goals the service market has when using brokers.

The paper has the following structure. First we discuss virtual brokers and the service industry and identify a list of outcomes that enable the development of social innovations. We then discuss the e-health market and describe how the aforementioned outcomes could enable the development and co-creation of social innovations for e-health. We then suggest specific requisites that the ehealth market should guarantee to attract the two sides of the market.

\subsection{Virtual Brokers and the Service Industry}

The number of stakeholders in the service industry have greatly increased and their interactions between these stakeholders has become more complex [18] [19]. This increase in complexity has made cooperation for innovation less straightforward. Virtual brokers ${ }^{4}$ are thus required to established links and to support the flow of information among the actors, but also to incentive them to enhance cooperation.

For many years the service industry has moved from push market to pull market that begins with the demand rather than the supply. In such a market, virtual platforms, are used as brokers that remove barriers for communication, build arenas for interaction between the two sides of the market, consumers and producers, and also offer the necessary marketing infrastructure that allows to

${ }^{4}$ The term "broker" has given rise to the connotation of virtual platforms that brings people together and that offers the possibility to strategically interact and match actors that pursue similar objectives. Brokers are facilitators of interaction and cooperation in innovation systems, and their activities extend throughout the two-sides of the market. 
diminishing commercialization efforts, the develop of innovative business models, the use of distribution channels that made the services universally accessible and that at the same time offer demand driver services [19]. The use of brokers has facilitate the development of a space where interactions can take place between stakeholders that are different enough to have new knowledge but related enough to understand each other. This leads to the creation of innovations in a many to many relationship as demanded by the service industry [20] where brokers are expected to have the role of "systemic intermediaries".

Brokers in the service industry, are however, not only platforms that facilitate interaction between different stakeholders, they also offer software applications, innovative supply chain models [12], and mechanism or strategies that allow the follow up and re-use of services for further innovate. The use of virtual brokers has resulted in that firms of different sizes can enter to the market and benefit from using common virtual platforms (the broker). Some of the benefits include the reduction of competitive constrains, access to broader network of actors who exchange ideas and values, and the support of public-private exchanges of knowledge and experience [17].

The use of brokers in the service industry has made it possible to:

- Provide a platform that enables producers and consumers interact with each other as they identify demand driven services.

- Provide access to an infrastructure that the consumers cannot access in single markets (one producer, one consumer).

- Signal relevant market activity that make the both sides valuable to join up the platform.

- Apply principles, policies, and use networks that encourage consumers to use and trust the broker.

- Use innovative business and payment models.

- Offer multi-homing alternatives through the presence of several providers and suppliers (multi-homing) that offer comparable services and that have similar degrees of acceptance among the consumers.

Virtual brokers further allow the service industry the possibility to change the structure of the industry. This has been realized in terms of vertical integration (for tighter control and higher profit extraction power) and in terms of vertical disintegration (by using licenses that help to expand the market) [19].

One of the most important characteristic that virtual brokers possessed is the fact that they are entrepreneur-focused (as opposed to simple business focused). They help innovators and entrepreneurs realize their initial ideas all the way through to products that directly benefit from such collaboration and networking. Consequently, the sustainability of the brokers, much depends on factors such as: the existence of corporate social responsibility, the existence of policies and guidelines to guarantee quality, security and safety issues of relevance for the two sided of the market, the existence of networks that guarantee transparency and prevent market inefficiencies (e.g. monopolies, cartel, and negative external 
effects) [21], and the capacity to guarantee the development of long-term strategic planning and a dynamic evolution of the market [22].

\subsection{Virtual Brokers and Social Innovations: Is the E-Health Market Ready to Use Virtual Brokers to Stimulate the Co-Creation of Social Innovations?}

Technological developments, innovations, and the use of electronic devices across the world provide numerous opportunities for prominent players in to the e-health market to achieve the goals of the e-Health Acton Plan, namely to innovate healthcare for the 21 century [6]. The increasing use of tablets, smart phones, as a quick and easy mode of communication is likely to supplement the growth of the market. However, concerns related to the lack of reimbursement policies and the absences of brokers who can facilitate interaction of the two sides of the market currently hamper growth in the e-health market place. Note that in this market innovations are created by using embedded knowledge from actors outside the boundaries of the organization [23] [24] [25] [26].

To meet the demands of this marketplace, a series of portals and virtual platforms, normally owned by healthcare authorities, county councils, insurance companies etc, has been globally and national developed. These portals and platforms usually allow free access for patients to, for instance, health record systems and advice from healthcare personnel. They are, however, not specifically built arenas or forum where interoperability or an interchange of knowledge between the two sides of the market can take place. Outputs from interviews with representatives from the two sides of the markets (customers and suppliers) and from the literature review performed in previous studies, as mentioned in the method chapter, shown that there are a number of challenges that are of key relevance for to achieve and develop a sustainable e-health market that can stimulate co-creation and at the same time produce and deliver social innovations.

In general it seems that the lack of arenas in which consumer and producers can communicate and interact [26] to reduce costs related to interoperability to develop demand driven social innovations, are the major issues that constrain the development of the e-health market today. Further, there seems to be a need for to clarify rules and for to develop structures and arena that can be used to support interoperability and interaction between consumers and providers to be able to access and use the embedded knowledge they have in order to develop demand driven services and social innovations [13] [24] [26]-[31]. The development of innovative and alternative business models that sustain alternative payment and reimbursement alternatives also seems to be important [32] for the two sides of the market. Not with standing this, the absence of information of specific laws and regulations for different contexts and organizations, as well as obstacles to communication due to a changing environmental and changes in the actors also poses problems for those who has the ambition to join the ehealth two-sided market of today [27] [28]. 
Comparing the outputs identified by providers and consumers in the studies focused in the e-health market, with the outcomes the use of virtual brokers have made possible for the service industry, it seems that there are no major differences between them (See the Table 1). An important question is how virtual brokers in e-health can meet demands of transparency in ownership, security and safety, and trust in communication [33]. Whilst simultaneously being subject to an open market that follows rules for the supply of services and regulates the entrance into the market.

Table 1. List of issues that are considered of key relevance by both sides of the e-health market and its correspondence with the main outcomes identified in the service industry as a consequence of the use of virtual brokers.

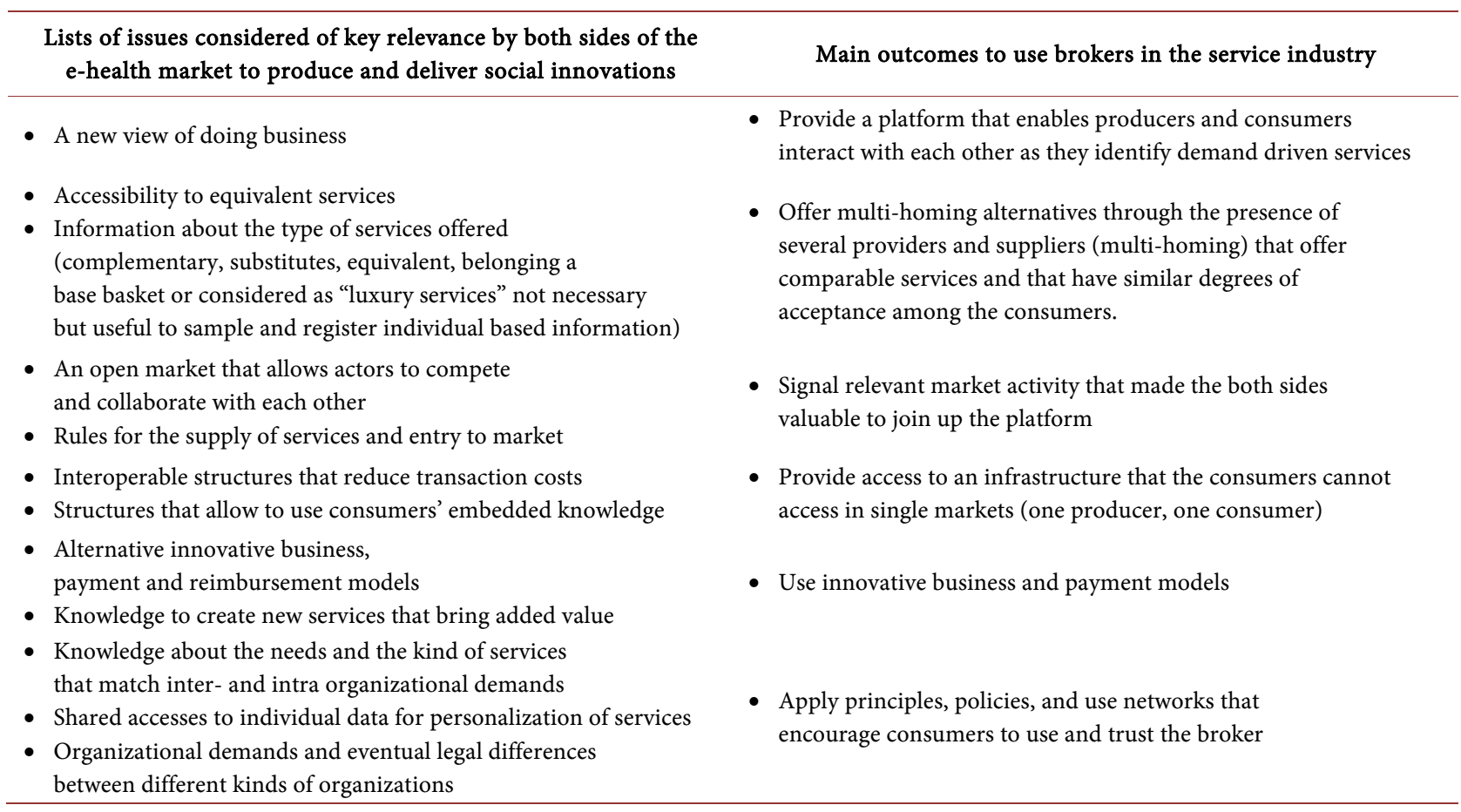

From the above, it seems rational to argue that brokers in the e-health market, in addition to facilitate an arena for interaction and co-creation of social innovations, need to guarantee the match between specific request that the e-health market presupposes and the demand of attracting firms and organization to produce and co-produce demand driven services. We suggest therefore, that ehealth brokers who want to develop a sustainable arena of interaction and cocreation where both sides of the market are present consider to:

- Develop guidelines and policies regarding ownership of services and pre-requisites for access to the market and clear stipulate whether.

o The services should be owned 1) by an intermediary (for example a county council, a healthcare unit, an insurance company, a pharmaceutical company); 2) by agents (for example a patient organization, or by the company that produce the service), or 3) whether an alternative ownership model should exist. 
o Contractual arrangements and property rights should be 1) generic or 2) specific depending the type of the services.

o Access to any virtual broker should be restricted to a limited number stakeholders of whether the broker will use an open source principle.

o Property rights are to be regulated by contracts or whether the services be open source.

- Offer Multi-home alternatives. In a market in which consumers' preferences are sufficiently homogenous (due the nature of the services offered) and given that they will guarantee quality, safely and privacy, the existence of several providers can contribute to an increase in social welfare. This is especially the case; if there are several providers of the same type of services that can guarantee the access to alterative that are equal equivalent to each other (" $\mathrm{mul}$ ti-homing") Multi-homing alternatives should further increase the degree of competition while contributing to diffuse innovations to a higher number of customers.

- Develop networks that diminish risks. The main challenge is the development of a coherent, sustainable and trusting arena were all relevant information can be transferred from all producers to all consumers in a structured, well defined, complete, and undistorted manner. To offer an arena for interaction that will attract risk-adverse actors, brokers will further need to guarantee the existence of several types of networks such as:

o Knowledge networks to develop new ways of thinking, where security and safety issues that can be helpful in solving transnational problems can be discussed. Knowledge networks should further support knowledge creation around products, services, goods and disseminate ideas for social innovation and order to align developers and customers" needs in a realistic manner.

o Policy networks to create policies even though they are not necessarily networks for government policy makers. Networks activities should cover the full range of steps in policy process (beyond to policy proposals) including agenda setting, policy formulation, rulemaking, coordination, implementation, and evaluation and developing of security policies and principles.

o Advocacy networks to change the agenda or policies of governments, corporations or other institutions. An advocacy network challenges business leaders to rethink not only their business strategy, but also their larger purpose and role in the global marketplace. Such a network should contributes to the visualization of important issues for the e-health area as well as the pre-requisites different health-care systems demand.

o Watchdog networks to ensure business of transparency, where institutions are scrutinized so as to ensure that they behave appropriately. Topics range from corruption and the environment to financial services. Customers and producers can evaluate the value of services at levels not possible before. The area for interaction the brokers offer should characterized as transparent, prepared for developing a brand or reputation that is sustainable over time, 
facilitates management systems, early warning systems and the visualization of open source support systems.

\section{Discussion}

While the e-health market is rapidly becoming fundamental to the provision of health and social care, efforts to establishing a market in which consumers and providers can interact with each other, benefit from each other and co-produce social innovations has increase. In view of the challenges the e-health market is confronted with as it strives to achieve sustainability, virtual brokers can have an strategic role to both accelerating the diffusion of services, and in facilitating interaction and in sustaining collaboration between the two sides of the market [34]. We thus consider the e-health market as a "pull market" in which consumers and producers interact with each other as they develop demand-driven services.

A mayor difficulty for the e-health market today, is the fact that many innovations are often incremental and form part of a continuous process of numerous small-scale advances. Outlooks of the-e-health market often discuss the need to covers several perspectives including political, technological, economic perspectives, and issues related to international cooperation, In addition, the needs to develop trust, security and cost-effectiveness of the services are also of importance. Furthermore, the e-health market needs to consider socio-technical and economic issues as it supports a sustainable relationship among the various industry participants, providers of e-health services and customers.

This is done so that the is able to solve externalities that affect the market, including laws, regulations, policies, market restrictions (for example, the price the consumers pay for the services, as in the case of the Scandinavian countries where the prices are regulated by policies and demand solutions such as subventions, roof prices, existence of public owned monopolies, etc.). The market must also improve operability so as to better maximize benefits for both sides of the market, namely the market and the individuals (consumers and patients) who use the e-health system.

From the interviews and the literature review that was previously performed, we learn that a general constrain for further development of the market is the absence of "connected services". The lack of information on whether some services will be complex, single, for example is also an issue because the level of responsibility providers can have. In today's market it is not clear who will be offering the services, how they will be accessible and how consumers' knowledge will be used to improve services. Entrepreneurs do not seems to be willing to both distribute and finance the services.

A central task for the future of the e-health market is, therefore, to actively investigate what services or social innovations consumers actually want. It is not longer an innovation to merely offer delivery of drugs or delivery of medical devices, or to offer "bank services" (i.e. online payment, etc.) and so on. The lack of 
capacity to capture embedded knowledge, individual preferences and attitudes [34], or knowledge about the inter-temporal use of e-health services, are major hurdles to enter the market. Consequently, considerable effort needs to be made in the future, if we are to better understand and integrate customer orientation into the design and deployment of e-health services and intermediary platforms.

Innovation researchers emphasize the importance of brokers in networks. Brokers connect stakeholders who are not familiar to each other but also allow them to improve upon the new combinations that are essential to the demand of innovation [34]. Virtual e-health brokers may bundle features that provide value to both sides of the market and maximize social welfare. Finally, because sustainable development of the e-health market depends a great deal upon the market structures that will be developed, the intermediaries will take the role as brokers and the development of infrastructures that allow information to flow within and between the two sided of the market. Learning from the service industry and extrapolating good experiences from this industry will allow us to avoid continuing to work with explorative approaches. Instead, concrete market innovations should be made. Much of the desired improved collaboration between the two sides of the e-health market requires a long-term perspective, and a willingness in investors that is based on the expectation that the collaboration will continue for a long time. It is rarely possible to specify in advance exactly how this might take place. If the service industry succeeds 1) in developing virtual brokers that work and 2) in developing co-owned joint ventures with guarantees of continued cooperation between their business partners, then the e-health market should definitely benefit from their experiences. The current imperfect interaction between the two sides of the e-health market is often not a result of unwillingness of the concerned parties to interact with each other, but of a lack of capacity, structures, and incentives to interact effectively. Enterprises or organizations that will play a role as virtual brokers in the future can close the gap. This will especially be the case if brokers can be shown to have a good reputation and a degree of independence from the major stakeholders in the process and the overall innovation system. This does not mean that brokers necessarily need to belong to specialized organizations, as is the case for the majority of the portals that have been developed in the area today. It can also be possible that organizations with legitimacy in the service area act at watchdog networks and guarantee the legitimacy of the brokers. In this context, they have an important potential role in contributing to the development of policies and guidelines and to the discussion of these policies and guidelines with industries and stakeholders who are interested in becoming brokers, locally and even globally.

\section{Conclusion}

The role of virtual brokers is essential for the evolution of the service market. They have contributed to the promotion of services; they match the demand 
with the best available services (based on customer needs and wants) and they provide the infrastructure that is needed to allow different parties to come into contact with each other, thereby reducing transaction costs and duplication costs. Virtual brokers also offer alternative business models. Virtual brokers have taken on the role of being "watchdogs", ensuring that the ecosystem that the broker offers are used to provide "good things", for example, by preventing market inefficiencies (e.g., monopolies, cartels, and negative external effects). Virtual brokers help in the continuous scaling of new collaborative ideas, encourage interoperability and cooperation among individuals, organizations and companies as they share information, build alliances, and develop complementary products and services. In further research it will be of interest to investigate if and how the two sides of the market are willing to use the brokers developed in the service industry to interact with each other and develop social innovations. It is also of importance to validate the theoretical assumptions that are presented in this paper with the industries, organizations, and customers, and to enquire of them which additional pre-requisites, if any, are necessary to consider as the e-health market continues to expand. Finally, it is also of relevance to sample knowledge about preferences regarding the type of brokers that will be chosen, whether they are private or public, or belong to companies that have not traditionally been active in the e-health market, but have experience in creating a space where providers and customers can meaningfully interact with each other.

\section{References}

[1] Koch, S. (2012) Improving Quality of Life through E-Health-The Patient Perspective. The 24th Medical Informatics in Europe Conference, Pisa, 2012, 25-29.

[2] Barry, M.J. and Edgman-Levitan, S. (2012) Shared Decision Making, the Pinnacle of Patient-Centered Care. New England Journal of Medicine, 366, 780-781. https://doi.org/10.1056/NEJMp1109283

[3] Berwick, D.M., Nolan, T.W. and Whittington, J. (2008) The Triple Aim: Care, Health, and Cost. Health Affairs, 27, 759-769. https://doi.org/10.1377/hlthaff.27.3.759

[4] Dwamena, F., Holmes-Rovner, M., Gaulden, C.M., Jorgenson, S., Sadigh, G., Sikorskii, A., Lewin, S., Smith, R.C., Coffey, J., Olomu, A. and Beasley, M. (2012) Interventions for Providers to Promote a Patient-Centred Approach in Clinical Consultations. Cochrane Database of Systematic Reviews, Cochrane.

[5] Tang, C., Lorenzi, N., Harle, C.A., Zhou, X. and Chen, Y. (2016) Interactive Systems for Patient-Centered Care to Enhance Patient Engagement. Journal of the American Medical Informatics Association, 23, 2-4. https://doi.org/10.1093/jamia/ocv198

[6] Health IT (2016) Meaningful Use Regulations. https://www.healthit.gov/policy-researchers-implementers/meaningful-use-regulati ons

[7] European Commission (2012) E-Health Action Plan 2012-2020-Innovative Healthcare for the 21st Century. Brussels, 1-14.

[8] Acheampong, F. and Vimarlund, V. (2014) Business Models for Telemedicine Services: A Literature Review. Health Systems, 4, 189-203. 
https://doi.org/10.1057/hs.2014.20

[9] Chesbrough, H.W. (2003) Open Innovation: The New Imperative for Creating and Profiting from Technology. Harvard Business School Press, Boston.

[10] Eysenbach, G. (2001) What Is E-Health? Journal of Medical Internet Research, 2001, 3. https://doi.org/10.2196/jmir.3.2.e20

[11] Grand View Research Inc (2016) Healthcare Mobility Solutions Market Size \& Forecast By Product \& Services (Mobile Devices, Mobile Applications, Enterprise Mobility Platforms) by Application (Enterprise Solutions, mHealth) by End Use, and Trend Analysis from 2014-2025.

http://www.grandviewresearch.com/industry-analysis/healthcare-mobility-solutions -market

[12] Bullinger, A.C., Rass, M., Adamczyk, S., et al. (2012) Open Innovation in Health Care: Analysis of an Open Health Platform. Health Policy, 105, 165-175. https://doi.org/10.1016/j.healthpol.2012.02.009

[13] Bullinger, A.C., Rass, M. and Moeslein, K. (2012) Towards Open Innovation in Health Care. The European Conference on Information Systems, Barcelona, 2012, 5-15.

[14] Kuenne, C.W., Moeslein, K. and Bessant, J. (2013) Towards Patients as Innovators: Open Innovation in Health Care. In: Mukhopadhyay, C., Akhilesh, K.B., Srinivasan, R., et al., Eds., Driving the Economy through Innovation and Entrepreneurship, Springer, New York, 315-327. https://doi.org/10.1007/978-81-322-0746-7 26

[15] Leonard, D. (1995) Wellsprings of Knowledge: Building and Sustaining the Sources of Innovation. Harvard Business School Press, Boston.

[16] Was. S and Vimarlund, V. (2016) Healthcare in the Age of Open Innovation. A Literature Review. Health Information Management Journal, 1-13.

[17] Was. S and Vimarlund, V. (2015) Challenges of Stimulating a Market for Social Innovation-Provision of a National Health Account. Proceedings of European Federation for Marical Informatics, Amsterdam, Madrid, 546-549.

[18] World Bank (2006) World Development Report. http://documents.worldbank.org/curated/en/435331468127174418/pdf/322040Worl d0Development0Report02006.pdf

[19] Nord, P. (2016) Consumer-Driven Logistics: Driving Forces and Challenges. White Paper.

http://www.postnord.com/globalassets/global/english/document/publications/2016/ whitepaper-about-consumer-driven-logistics-october-2016.pdf

[20] Granovetter, M. (1985) Economic Action and Social Structure: The Problem of Embeddedness. American Journal of Sociology, 91, 481-510. https://doi.org/10.1086/228311

[21] Shapiro, C. and Variant, H.R. (1991) Information Rules. Harvard Business School Press, Boston.

[22] Evans, D.S. (2007) Some Empirical Aspects of Multi-Sided Platform Industries. Review of Network Economics, 2, 191-209.

[23] Gassmann, O. and Enkel, E. (2004) Towards a Theory of Open Innovation: Three Core Process Archetypes. The R\&D Management Conference, Lisbon, 7-9 July 2004.

[24] Rubinelli, S., Collm, A., Glassel, A., et al. (2013) Designing Interactivity on Consumer Health Websites: Paraforum for Spinal Cord Injury. Patient Education and 
Counseling, 93, 459-463. https://doi.org/10.1016/j.pec.2013.09.015

[25] Salge, T.O., Farchi, T., Barrett, M.I., et al. (2013) When Does Search Openness Really Matter? A Contingency Study of Health-Care Innovation Projects. Journal of Product Innovation Management, 30, 659-676. https://doi.org/10.1111/jpim.12015

[26] Zachariadis, M., Oborn, E., Barrett, M., et al. (2013) Leadership of Healthcare Commissioning Networks in England: A Mixed Methods Study on Clinical Commissioning Groups. BMJ Open, 3, e002112.

https://doi.org/10.1136/bmjopen-2012-002112

[27] Davey, S., Brennan, M., Meenan, B.J., et al. (2001) Innovation in the Medical Device Sector: An Open Business Model Approach for High-Tech Small Firms. Technology Analysis and Strategic Management, 23, 807-824.

[28] Dias, C. and Escoval, A. (2012) The Open Nature of Innovation in the Hospital Sector: The Role of External Collaboration Networks. Health Policy and Technolo$g y$, 1, 181-186. https://doi.org/10.1016/j.hlpt.2012.10.002

[29] Dandonoli, P. (2013) Open Innovation as a New Paradigm for Global Collaborations in Health. Globalization and Health, 9, 1-5.

https://doi.org/10.1186/1744-8603-9-41

[30] Kuenne, C.W., Moeslein, K. and Bessant, J. (2013) Towards Patients as Innovators: Open Innovation in Health Care. In: Mukhopadhyay, C., Akhilesh, K.B., Srinivasan, R., et al., Eds., Driving the Economy through Innovation and Entrepreneurship, Springer, New York, 315-327. https://doi.org/10.1007/978-81-322-0746-7 26

[31] Meersman, D. and Leenheer, P. (2012) Open Innovation in Health Service Value Networks: A Methodology for the Innovation of Ambient Assisted Living Platforms and Services, Abramowicz Health Information. Business Information Systems Workshops, Springer, Berlin, 25-36.

[32] Zott, C., Amit, R. and Massa, L. (2011) The Business Model: Recent Developments and Future Research. Journal of Management, 37, 1019-1042. https://doi.org/10.1177/0149206311406265

[33] Anandajayasekeram, P. (2011) Agricultural Services and Technology Innovations. https://innovationpolicyplatform.org/sites/default/files/rdf imported documents/A gricultural Innovation Brokers.pdf

[34] Vimarlund, et al. (2016) E-Health Two-Sided Markets-Implementation and Business Models. Elsevier, Amsterdam. 
Submit or recommend next manuscript to SCIRP and we will provide best service for you:

Accepting pre-submission inquiries through Email, Facebook, LinkedIn, Twitter, etc. A wide selection of journals (inclusive of 9 subjects, more than 200 journals)

Providing 24-hour high-quality service

User-friendly online submission system

Fair and swift peer-review system

Efficient typesetting and proofreading procedure

Display of the result of downloads and visits, as well as the number of cited articles Maximum dissemination of your research work

Submit your manuscript at: http://papersubmission.scirp.org/

Or contact iim@scirp.org 